\title{
Prevalence and Factors Associated with Hypertension among Elderly Population in Dhapasi VDC of Kathmandu District
}

\section{Sunita Dhakal ${ }^{1 *}$, Rakesh Singh ${ }^{2}$, Uday Naryan Yadav ${ }^{3}$ and Lekh Bahadur Gurung ${ }^{1}$}

${ }^{1}$ Department of Public Health, Manmohan Memorial Institute of Health Sciences, Kathmandu

${ }^{2}$ Department of Community Medicine, National Medical College, Birgunj

${ }^{3}$ Forum for Health Research and Development, Dharan, Nepal

\begin{abstract}
Ageing is closely associated with the dynamic demographic and socio-economic transformation. In the elderly period hypertension is the problem related with the internal features of the body. The objective of the study was, to find out the prevalence and factors associated with hypertension among elderly population. The descriptive, crosssectional study was carried out in Dhapasi VDC among 318 elderly people selected by systematic random sampling. Ethical approval was obtained from the institutional review committee of Chitwan Medical College, Chitwan, Nepal. Data were collected through face to face interview technique using semi-structured schedule and analysis was done in SPSS version 16.0 . The results unveiled that $56.9 \%$ of the elderly people were hypertensive, among them $40.8 \%$ of the respondents were diagnosed during the study, $29.6 \%$ were diagnosed before the study and $13.5 \%$ were diagnosed before and during the study. The prevalence of hypertension among smokers was $63.4 \%$, those who were not involved in regular physical exercise was $63.8 \%$, among those who took fat containing food more than three times in a week were $61.7 \%$, who have disturbed sleep were $62 \%$, who were the patients of diabetes was $90.0 \%$ and among those who have other co-morbidities was $38.7 \%$. The prevalence of hypertension was found to be higher among elderly people. So, the study suggests that hypertension should be controlled especially with a focus to elderly population.
\end{abstract}

Keywords: Elderly; Hypertension; Prevalence

\section{Introduction}

Ageing is a natural phenomenon and inevitable process. It is closely related with the dynamic process of demographic and socio-economic transformation [1]. The prevalence of hypertension increases with age, as does the incidence of the diseases caused by hypertension. Older people are more likely than younger people to have hypertension and to benefit from treatment to bring blood pressure at normal. Prevention and treatment of hypertension and target organ disease remain important public health challenges that must be addressed. An important area for improving the control of blood pressure is among older people. The results in the trials of antihypertensive therapy follow a common and consistent Pattern and the benefits are greater in studies which select older patients [2].

Blood pressure means the lateral pressure exerted by blood flowing in the arteries on the arterial wall. Systolic BP: when the heart is pushing blood through the arterial system; and diastolic BP: when the arteries are at rest and the heart is refilling.

\section{Normal: Systolic 90-140 and Diastolic 60-90 mmHg}

Hypertension is the term used to describe blood pressure equals to $140 / 90$ or above [3]. Hypertension become more common with increased age and more than $50 \%$ of people over the age of 65 years suffer from it however majority of this hypertensive people are undiagnosed or uncontrolled [4].

According to Global status report on non-communicable diseases 2011, WHO, hypertension is a major risk factor for cardiovascular disease. Worldwide, raised blood pressure is estimated to cause 7.5 million deaths, about $12.8 \%$ of the total of all annual deaths. This accounts for 57 million DALYs or 3.7\% of total DALYs. Raised blood pressure is a major risk factor for coronary heart disease and ischemic as well as hemorrhagic stroke [5].

Ageing population, rapid urbanization and transition from agrarian life to a wage-earning, modern city life are reported as major contributors to increased blood pressure in urban areas. The prevalence of raised blood pressure in low, lower-middle and upper-middle income countries is higher (40\%) than in high-income countries (35\%). In high-income countries, strong public health policies, multisector preventive action and widely available diagnosis and treatment have led to a reduction in the prevalence of high blood pressure. In contrast, in many developing countries the disease burden caused by raised blood pressure has increased over the past decade [6].

The prevalence of Non-Communicable Disease is increasing in Nepal. In 2008, nearly $50 \%$ of total deaths in Nepal were estimated to be due to NCDs and Cardio Vascular Disease (CVD) accounted for 25\% of these deaths. Hypertension, one of the major risk factor for CVD, was estimated to be present in $27.8 \%$ of Nepalese adults aged 25 years and above [7].

The first scientific hypertension survey in Nepal, done in 1981 by Mrigendra Samjhana Medical trust. The prevalence of hypertension according to the then used World Health Organization (WHO) a criterion $(160 / 95 \mathrm{mmHg})$ in the different geographical settings of the country indicates towards a high prevalence of hypertension in the Nepalese population [8].

As the number of older people increases, several old age related

*Corresponding author: Sunita Dhakal, Department of Public Health, Manmohan Memorial Institute of Health Sciences, Kathmandu, Nepal, Tel: +977 1-4030782 E-mail: sunitadhakal257@gmail.com

Received July 31, 2017; Accepted September 09, 2017; Published September 12, 2017

Citation: Dhakal S, Singh R, Yadav UN, Gurung LB (2017) Prevalence and Factors Associated with Hypertension among Elderly Population in Dhapasi VDC of Kathmandu District. J Hypertens (Los Angel) 6: 242. doi: 10.4172/21671095.1000242

Copyright: ( 2017 Dhakal S, et al. This is an open-access article distributed under the terms of the Creative Commons Attribution License, which permits unrestricted use, distribution, and reproduction in any medium, provided the original author and source are credited. 
Citation: Dhakal S, Singh R, Yadav UN, Gurung LB (2017) Prevalence and Factors Associated with Hypertension among Elderly Population in Dhapasi VDC of Kathmandu District. J Hypertens (Los Angel) 6: 242. doi: 10.4172/2167-1095.1000242

Page 2 of 4

problems have emerged in our society. Out of total population of Nepal 27.8 million (2013, central bureau of statistics, Nepal) the population of 60 years and over is $21,54,410(8.14 \%)$ [9], the objective of the study was, to find out the prevalence and factors associated with hypertension among elderly population.

\section{Materials and Methods}

A cross sectional study was conducted in Dhapasi VDC of Kathmandu District, Nepal, from $14^{\text {th }}$ September to $21^{\text {st }}$ October, 2013. The study population were people who were 60 years of age and above. Systematic random sampling method was adopted during the study. The total household of the VDC were obtained from the VDC profile which was the sampling frame for the study. There were total nine wards in this VDC. Sampling frame was the list of total households in VDC. A list of total household of the VDC $(\mathrm{N}=3,154)$. The sampling unit was obtained using systematic random sampling assuming every household have elderly person and if elderly person was not found in that household a nearby house in front of that house was taken as sample. The first household was selected randomly and other households were selected at an interval of 10 households, $\left(K^{\text {th }}\right.$ item $=3,154 / 318=9.91824=10^{\text {th }}$ item) until the required sample size was met.

The study design was cross-sectional and descriptive in nature. The study site was Dhapasi VDC of Kathmandu District, Nepal. The different criteria that were used for the estimation of the sample size were as follows:

Desired confidence limit-95\%

Total elderly population in the VDC $=11,022$

Total households in that VDC $=3,154$

Allowable error $=15 \%$

Taking above criteria in consideration, total number of sample, required for this study was determined by using the formula:

$\mathrm{n}=$ required sample size

\section{$\mathrm{z}=1.96$ for $95 \%$ confidence level}

$\mathrm{p}=$ prevalence of hypertension among elderly population $(32.5 \%)$ "Prevalence and determinants of hypertension and diabetes among elderly population in the Kathmandu valley of Nepal" [10].

$\mathrm{d}=$ precision or error allowed in the study $=15 \%$ of $\mathrm{p}=0.15$ of $\mathrm{p}=0.04875$ $=354$

$\mathrm{q}=(1-\mathrm{p}), \mathrm{n}=\mathrm{z}^{2} \times \mathrm{pq} / \mathrm{d}^{2}=(1.96)^{\star}(1.96)^{\star} 0.325^{\star} 0.675 / 0.04875^{\star} 0.04875$

$\mathrm{N}=3,154$ (Total household in Dhapasi VDC)

Sample size $(\mathrm{n})=\mathrm{n}_{0} / 1+\mathrm{n}_{0} / \mathrm{N}$

Desired sample size $=354 / 1+354 / 3154=318$

Sample size of each ward was calculated by formula=Total sample size/Total household of the VDC $\times$ Total household of that ward. Dhapasi VDC was selected purposively. Face-face interview was used as a technique for data collection. Data were collected through semistructured questionnaire by direct interview. Collected data were entered and analyzed in the SPSS version 16.0.

Height of the respondents was measured by using non-stretch TR 13 Tailors Tape with $1 / 2$ inch width. Weight of the respondents was taken by weighing machine. Blood pressure was measured two times by cuff- mounted aneroid sphygmomanometer $0-300 \mathrm{mmHg}$ / vaquez-laubry classic and stethoscope, following WHO JNC, VII criteria. Pretesting was done in $10 \%$ of sample size in Shivanagar VDC of Chitwan District, Nepal.

\section{Results}

Socio-demographic and behavioral characteristics, food habit and personnel health of study population

Among total, $48.1 \%$ of the respondents are in the age group 60 69 and $78.3 \%$ are married. About 19.8\% of the respondents have smoking habit, $24.2 \%$ have alcohol drinking habit, $44.3 \%$ have habit of doing regular physical exercise, $87.1 \%$ slept more than 8 hours and $67 \%$ experienced disturbed sleep. About $90.3 \%$ of the respondent takes carbohydrate containing foods daily, $32.7 \%$ takes fruits sometimes, $27 \%$ takes fat containing foods daily, $41.5 \%$ have never taken meat and $5.3 \%$ takes vegetables daily. About $16 \%$ of the respondents have suffered from any type of disease, $6.3 \%$ have suffered from diabetes, $2.5 \%$ have suffered from asthma, $2.8 \%$ have suffered from knee arthritis, $2.2 \%$ have suffered from heart disease, $0.6 \%$ has suffered from TB and $1.6 \%$ has suffered from incontinence of urine. Among total $36.2 \%$ of the respondents who were suffered from hypertension at present. Respondents suffering from hypertension and taking medicine at present $(n=115)$ (old hypertensive number) was $81.7 \%$, it was found that $40.9 \%$ were hypertensive and $59.1 \%$ were non-hypertensive, $59.1 \%$ were found to be non-hypertensive, Respondents who were diagnosed as hypertensive before the survey and during the survey too were $13.5 \%$, Respondents who are diagnosed as hypertensive during the survey only were $27.3 \%$, Respondents who are diagnosed as hypertensive before the survey only were $16.1 \%$, Proportion of total Hypertensive Elderly People $(n=318)$ is $56.9 \%$, Proportion of total Non-Hypertensive Elderly People $(\mathrm{n}=318)$ is $43.1 \%$, Proportion of Hypertension among male $(\mathrm{n})=152$ is $50.3 \%$, Proportion of Hypertension female $(n)=166$ is $49.7 \%, 2 \%$ of the respondents have Family members suffered from hypertension in the family of respondents before the survey, $11 \%$ of the respondents have family members suffered from hypertension during the survey, hypertension while measuring BMI (Basic Metabolic Index) $(n=318)$ it was found that $17.9 \%$ were overweight, $12.6 \%$ were obese, $67 \%$ have normal BMI and $2.5 \%$ were under weight for age.

\section{Factors associated with hypertension}

Crude odds ratio and 95\% confident interval were calculated to measure the strength of association between hypertension and its associated factors (Table 1).

\section{Bivariate analysis}

Table 2 shows crude odds ratio with $95 \%$ confidence interval of hypertension across different variables.

\section{Multivariate analysis}

To identify the independent effect of each of the independent variables and to identify the most significant predicator of the hypertension, multiple regression analysis was done (Table 3 ).

\section{Logistic regression equation is as follows:}

$$
\mathrm{Y}=\beta_{0}+\beta_{1} \mathrm{X}_{1}+\beta_{2} \mathrm{X}_{2}+\ldots \ldots \ldots \ldots \ldots \ldots \beta_{\mathrm{n}} \mathrm{X}_{\mathrm{n}}
$$

Where, $Y=$ dependent variable, $\beta_{0}=$ constant. $\quad \beta_{1}, \beta_{2} \ldots \ldots$. $\beta=$ Regression coefficient for explanatory variables, $X_{1}$ and $\mathrm{X}_{2}=$ explanatory variables 
Citation: Dhakal S, Singh R, Yadav UN, Gurung LB (2017) Prevalence and Factors Associated with Hypertension among Elderly Population in Dhapasi VDC of Kathmandu District. J Hypertens (Los Angel) 6: 242. doi: 10.4172/2167-1095.1000242

\begin{tabular}{|c|c|c|c|}
\hline Characteristics $(n=318)$ & $\begin{array}{c}\text { Non- } \\
\text { Hypertensive } \\
\text { N (\%) }\end{array}$ & $\begin{array}{l}\text { Hypertensive } \\
\text { N (\%) }\end{array}$ & P-Value \\
\hline \multicolumn{4}{|l|}{ Marital Status } \\
\hline Married & 118(47.4\%) & 131(52.6\%) & \\
\hline Widow/Widower & $19(27.5 \%)$ & $50(72.5 \%)$ & 0.003 \\
\hline \multicolumn{4}{|l|}{ Smoking Habit } \\
\hline Non Smoker & $77(50 \%)$ & $77(50 \%)$ & \\
\hline Smoker & $60(36.6 \%)$ & $104(63.4 \%)$ & 0.016 \\
\hline \multicolumn{4}{|l|}{ Habit of Exercise } \\
\hline No & $64(36.2 \%)$ & $113(63.8 \%)$ & \\
\hline Yes & $73(51.8 \%)$ & $68(48.2 \%)$ & 0.005 \\
\hline \multicolumn{4}{|c|}{$\begin{array}{l}\text { Habit of taking Fat Containing } \\
\text { Foods }\end{array}$} \\
\hline$\leq 3$ times a week & $57(52.3 \%)$ & $52(47.7 \%)$ & \\
\hline$>3$ times a week & $80(38.3 \%)$ & $129(61.7 \%)$ & 0.017 \\
\hline \multicolumn{4}{|l|}{ Disturbed Sleep } \\
\hline No & $56(53.3 \%)$ & $49(46.7 \%)$ & \\
\hline Yes & $81(38 \%)$ & $132(62 \%)$ & 0.010 \\
\hline \multicolumn{4}{|l|}{ Co-Morbidity(n=51) } \\
\hline Other than Diabetes & $19(61.3 \%)$ & $12(38.7 \%)$ & \\
\hline Diabetes & $2(10 \%)$ & $18(90 \%)$ & $<0.001$ \\
\hline \multicolumn{4}{|l|}{ BMI } \\
\hline Normal & $103(48.4 \%)$ & $110(51.6 \%)$ & \\
\hline Over Weight & $19(33.3 \%)$ & $38(66.7 \%)$ & \\
\hline Obese & $7(17.5 \%)$ & $33(82.5 \%)$ & 0.001 \\
\hline
\end{tabular}

Table 1: Factors associated with hypertension.

\begin{tabular}{|c|c|c|c|c|}
\hline Characteristics $(n=318)$ & $\begin{array}{c}\text { Non- } \\
\text { Hypertensive } \\
\text { N (\%) }\end{array}$ & $\begin{array}{c}\text { Hypertensive } \\
\text { N (\%) }\end{array}$ & OR & $95 \% \mathrm{Cl}$ \\
\hline \multicolumn{5}{|l|}{ Marital status } \\
\hline Married & $118(47.4 \%)$ & $131(52.6 \%)$ & 1 & \\
\hline Widow/Widower & $19(27.5 \%)$ & $50(72.5 \%)$ & 2.370 & $\begin{array}{l}1.322- \\
4.250\end{array}$ \\
\hline \multicolumn{5}{|l|}{ Smoking habit } \\
\hline Non Smoker & $77(50.0 \%)$ & $77(50.0 \%)$ & 1 & \\
\hline Smoker & $60(36.6 \%)$ & $104(63.4 \%)$ & 1.733 & $\begin{array}{l}1.107- \\
2.713\end{array}$ \\
\hline \multicolumn{5}{|l|}{ Habit of Exercise } \\
\hline Yes & $73(51.8 \%$ & $68(48.2 \%)$ & 1 & \\
\hline No & $64(36.2 \%)$ & $113(63.8 \%)$ & 1.895 & $\begin{array}{l}1.208- \\
2.975\end{array}$ \\
\hline \multicolumn{5}{|l|}{$\begin{array}{l}\text { Habit of taking Fat } \\
\text { containing foods }\end{array}$} \\
\hline$\leq 3$ times a week & $57(52.3 \%)$ & $52(47.7 \%)$ & 1 & \\
\hline$>3$ times a week & $80(38.3 \%)$ & $129(61.7 \%)$ & 1.768 & $\begin{array}{l}1.107- \\
2.823\end{array}$ \\
\hline \multicolumn{5}{|l|}{ Disturbed Sleep } \\
\hline No & $56(53.3 \%)$ & $49(46.7 \%)$ & 1 & \\
\hline Yes & $81(38.0 \%)$ & $132(62.0 \%)$ & 1.862 & $\begin{array}{l}1.161- \\
2.988\end{array}$ \\
\hline \multicolumn{5}{|l|}{ Co-Morbidity } \\
\hline Other than Diabetes & $19(61.3 \%)$ & $12(38.7 \%)$ & 1 & \\
\hline Diabetes & $2(10 \%)$ & $18(90 \%)$ & 17.100 & $\begin{array}{l}3.286- \\
88.985\end{array}$ \\
\hline \multicolumn{5}{|l|}{ BMI } \\
\hline Normal & $103(48.4 \%)$ & $110(51.6 \%)$ & 1 & \\
\hline Over Weight & $19(33.3 \%)$ & $38(66.7 \%)$ & 1.873 & $\begin{array}{l}1.015- \\
3.456\end{array}$ \\
\hline Obese & $7(17.5 \%)$ & $33(82.5 \%)$ & 4.414 & $\begin{array}{l}1.870- \\
10.418\end{array}$ \\
\hline
\end{tabular}

Table 2: Bivariate analysis of factors associated with hypertension.
So, the final multiple binary logistic regression models are given by: Hypertension $=-2.591+2.778$ (being patient of diabetes) +2.292 (taking fat containing foods more than three times in a week).

\section{Discussion}

The mean BMI of the subjects in our study population was $23.12 \mathrm{~kg} /$ $\mathrm{m}^{2}$, with a standard deviation of 3.4. The mean age of the respondents in this study is 70.62 years. This study revealed that of the 318 elderly people (female $=166$ and male $=152$ ), 181 were found to be hypertensive (male $=91(50.3 \%)$ and female $=90(52.6 \%)$ and among the hypertensive population, $51(29.6 \%)$ of them were diagnosed before the survey and $87(40.8 \%)$ of them were diagnosed during the survey and 43 (13.5\%.) of them diagnosed before and after the survey.

A similar study was conducted in Kathmandu valley, "Prevalence and determinants of hypertension and diabetes among elderly population in the Kathmandu Valley of Nepal". The total number of participants randomly selected for the study were 1633 aged 60 years and above (female $=899$, male $=734$ ), (mean age $=66$ years) in urban and rural areas of the Kathmandu valley. Which showed that the prevalence of hypertension was $32.5 \%$ diagnosed before the study and $22.4 \%$ diagnosed during the study. The prevalence of hypertension among male is $54.1 \%$ and among female $55.5 \%$ [10].

In our study we found that there is significant association between hypertension and diet containing fat. After adjusting with other independent variables it was found that elderly people who consume fat containing foods more than three times in a week were ten times more likely to be hypertensive then those who consume fat containing foods less than or equal to three times a week with $(A O R=10.023)$, $(\mathrm{CI}=1.048-95.890)$ and $\mathrm{p}$-value 0.017. A similar study was conducted in two regions of central Nepal: Kathmandu and Dhulikhel of Kathmandu valley. "Dietary factors associated with Hypertension in Nepal". The study revealed that, the respondents who takes whole dairy products once a month/seldom were more likely to be hypertensive then who never takes whole dairy products with odds ratio 1.85 and CI $(0.62$ 4.83). Respondents who take whole dairy products once a week were more likely to be hypertensive then who never takes whole dairy products with odds ratio 4.08 and CI $(0.52-30.60)$. The p-value is 0.92 [11]. This study revealed that the participants who were the patients of diabetes were 16 times more likely to be hypertensive then who were the patients of other diseases with $(\mathrm{AOR}=16.322)$ and $\mathrm{CI}(2.321-114.771)$.

A similar study was conducted in India and Bangladesh, "Evaluate the prevalence, awareness, treatment and control of hypertension among elderly individuals in Bangladesh and India”. A Communitybased sample of 1,203 elderly individuals (670 women; mean age, 70 years) was selected using a multistage cluster sampling technique from two sites in Bangladesh and three sites in India. The study revealed that, the overall prevalence of hypertension (WHO-International Society for Hypertension criteria) was $65 \%$ (95\% confidence interval $=$ 62-67\%). Multiple logistic regression analyses identified a higher body mass index, higher education status and prevalent diabetes mellitus as important correlates of the prevalence of hypertension. Physical activity, rural residence, and current smoking were inversely related to the prevalence of hypertension [12].

\section{Conclusion}

The result unveiled that the prevalence of hypertension was $27.3 \%$, diagnosed during the study only and $16.1 \%$ diagnosed before the study only and $13.5 \%$ of the respondents were diagnosed during the study and before the study too. Regular physical exercise, consuming vegetables 
Citation: Dhakal S, Singh R, Yadav UN, Gurung LB (2017) Prevalence and Factors Associated with Hypertension among Elderly Population in Dhapasi VDC of Kathmandu District. J Hypertens (Los Angel) 6: 242. doi: 10.4172/2167-1095.1000242

Page 4 of 4

\begin{tabular}{|c|c|c|c|c|}
\hline Characteristics $(n=318)$ & Non-Hypertensive $\mathbf{N}(\%)$ & Hypertensive N (\%) & Crude Odds Ratio $(95 \% \mathrm{Cl})$ & $\begin{array}{c}\text { Adjusted Odds Ratio } \\
(95 \% \mathrm{Cl})\end{array}$ \\
\hline \multicolumn{5}{|l|}{ Marital Status } \\
\hline Married & $118(47.4 \%)$ & $131(52.6 \%)$ & 1 & 1 \\
\hline Widow/Widower & $19(27.5 \%)$ & $50(72.5 \%)$ & $2.370(1.322-4.250)$ & $0.429(0.062-2.966)$ \\
\hline \multicolumn{5}{|l|}{ Smoking Habit } \\
\hline Non Smoker & $77(50.0 \%)$ & $77(50.0 \%)$ & 1 & 1 \\
\hline Smoker & $60(36.6 \%)$ & $104(63.4 \%)$ & $1.733(1.107-2.713)$ & $2.304(0.294-18.049)$ \\
\hline \multicolumn{5}{|l|}{ Habit of Exercise } \\
\hline Yes & $73(51.8 \%)$ & $68(48.2 \%)$ & 1 & 1 \\
\hline No & $64(36.2 \%)$ & $113(63.8 \%)$ & $1.895(1.208-2.975)$ & $0.547(0.067-4.435)$ \\
\hline \multicolumn{5}{|l|}{$\begin{array}{l}\text { Habit of taking fat Containing } \\
\text { Foods* }\end{array}$} \\
\hline$\leq 3$ Times a day & $57(52.3 \%)$ & $52(47.7 \%)$ & 1 & 1 \\
\hline$>3$ Times a day & $80(38.3 \%)$ & $129(61.7 \%)$ & $1.768(1.107-2.823)$ & $10.023(1.048-95.890)$ \\
\hline \multicolumn{5}{|l|}{ Disturbed Sleep } \\
\hline No & $56(53.3 \%)$ & $49(46.7 \%)$ & 1 & 1 \\
\hline Yes & $81(38.0 \%)$ & $132(62.0 \%)$ & $1.862(1.161-2.988)$ & $1.547(0.157-15.207)$ \\
\hline \multicolumn{5}{|l|}{ Co-morbidity* } \\
\hline Other than Diabetes & $19(61.3 \%)$ & $12(38.7 \%)$ & 1 & 1 \\
\hline Diabetes & $2(10.0 \%)$ & $18(90.0 \%)$ & $17.100(3.286-88.985)$ & $16.322(2.321-114.771)$ \\
\hline \multicolumn{5}{|l|}{ BMI } \\
\hline Normal & $103(48.4 \%)$ & $110(51.6 \%)$ & 1 & 1 \\
\hline Over Weight & $19(33.3 \%)$ & $38(66.7 \%)$ & $1.873(1.015-3.456)$ & $0.502(0.020-12.375)$ \\
\hline Obese & $7(17.5 \%)$ & $33(82.5 \%)$ & $4.414(1.870-10.418)$ & $0.267(0.008-8.872)$ \\
\hline
\end{tabular}

Note: 1-Reference Category, * significant, Nagelkerke R Square (0.556), Cox \& Snell R Square (0.411), Hosmer and Lemeshow test-0.200

Table 3: Multivariate analysis of factors associated with hypertension.

and fruits in the daily diet, not smoking, having undisturbed sleep and maintaining balanced sugar level in the blood are found to be the best measures for controlling hypertension.

So, intervention should be directed towards the health of elderly people from national level. Greater emphasis needs to be placed on promoting good health across the course of a lifetime, rather than on episodic care.

\section{Acknowledgment}

We would like to acknowledge all the participants for their valuable time for taking part in this study and making it successful.

\section{Author Contributions}

Dhakal S: Technicalities of the study, Singh R: Article preparation, Yadav UN Additional support

\section{Disclosure}

The author reports no conflicts of interest in this work.

\section{References}

1. Subedi RK (2010) Prevalence of insomnia and factors associated with it among elderly people of sarangdanda VDC in Panchthar district. Dhaulagiri J Sociology and Anthropology 4: 129-142.

2. James K, Donna LH (2002) Housing and health: Time again for public health action. Am J Public Health 92: 758-768.
3. American Heart Association (2003) Hypertension prevalence awareness and treatment.

4. Nikolaos L, Dimitrios M, Elias S, Georgios F, Maria G (2012) Hypertension in the elderly. World J Cardiol 4: 135-147.

5. World Health Organization (2010) Global status report on non-communicable diseases (2010) World Health Organization, Geneva.

6. World Health Organization (2011) Non communicable diseases in the SouthEast Asia Region: Situation and response.

7. Dhital SM, Karki A (2013) Dealing with the burden of hypertension in Nepal: Current status, challenges and health system issues. Regional Health Forum 17: 44-52.

8. Vaidya A, Ramji P, Pandey MR (2012) Prevalence of hypertension in Nepalese community triples in 25 years. Indian Heart J 64: 128-131.

9. Central Bureau of Statistics (2012) NPHC: National Population and Housing Census (National Report). Government of Nepal, National Planning Commission Secretariat.

10. Chhetri MR, Chmapman R (2009) Prevalence and determinants of hypertension and diabetes among elderly population in the Kathmandu valley of Nepal Nepal Med Coll J 11: 34-38.

11. Shrestha A, Annette L, David FS (2012) Siscovick dietary factors associated with Hypertension in Nepal. Master of Public Health Thesis, University of Washington.

12. Hypertension Study Group (2001) Prevalence, awareness, treatment and control of hypertension among the elderly in Bangladesh and India. Bull World Health Organ 79: 490-500. 